\title{
Realization of Fractance Device using Fifth Order Approximation
}

\author{
B.T. Krishna \\ Department of E.C.E \\ Jawaharlal Nehru Technological University Kakinada \\ Kakinada, Andhrapradesh \\ India-533003
}

\begin{abstract}
The realization of Fractance device is an important topic of research for the people working in Fractional Calculus, control systems, signal processing, and other allied fields. Having multifaceted applications, the realization of the device has gained importance from the past few years. The important step in the realization of Fractance device is finding the rational approximation that best fits its behavior. In this paper, the rational approximation is calculated using the continued fraction expansion formula. The rational approximation thus obtained is synthesized as a passive circuit using MATLAB. The active circuit is obtained by making use of the Operational Amplifier. The passive active circuits are simulated using TINA-TI software. The working of the proposed circuits is studied. It has been observed that both theoretical and simulated results match each other.
\end{abstract}

\section{General Terms}

Continued Fraction Expansion, Rational Approximation, Fractional order systems, Fractance device

\section{Keywords}

Fractional order, Resistance, Capacitance, Active circuit, Passive Circuit, Realization, Phase response

\section{INTRODUCTION}

Fractional calculus deals with the differentiation and integration to an arbitrary order[1-2]. The equation which contains fractional order differentiation and integration is called as Fractional order Equation. Any system which is defined by the Fractional order differential equation is called as a Fractional order system. Transmission lines, Diffusion of heat into solids, $\mathrm{PI}^{\lambda} \mathrm{D}^{\mu}$ controllers are some of the examples of Fractional order systems [3,4]. Some of the possible applications of the Fractional Calculus are discussed in detail in [3].

Fractance device is also an example of Fractional order System. The device is defined by the impedance which is proportional to $1 / \mathrm{s}^{\alpha}$, where $\alpha$ is a fractional order. As the value of the $\alpha$ changes, the behavior of the fractance changes. At $\alpha=0$, it behaves as a resistor. When $\alpha$ changes from -1 to +1 its behavior changes from inductor to capacitor. It acts as a Frequency dependent Negative Resistor (FDNR) when $\alpha=-$ $2[9,10]$. Since a mixed behavior is present in a single element the realization of the element has gained interest. For an ideal Fractance device the phase angle is constant independent of the frequency range of operation. But the phase angle depends only on the value of fractional order. So fractance device is also called as constant phase angle device or simply fractor [11,12,13]. In [17], Karabi Biswas et.al has proposed a commercially available fractance device and studied its operation and performance with respect to a differentiator circuit. This is preliminary attempt and the commercially available device need to be yet investigated. Fractional order Lowpass, Highpass and other types of filters are also possible with Fractance device[14,15,16,17]. Time domain response calculations of the Fractance device are presented in [18].

The realization of Fractance is possible with passive elements connected in different manners. Fractance device can be of tree type or chain type .M.Nakagawa and K.Sorimachi, have proposed a circuit consisting of self-similar tree type circuit with resistors and capacitors [34].Oldham and spanier have realized fractance circuit using $N$ pairs of $R C$ connected as chain network [16] .Recently a net grid type circuit for the realization of fractance device is proposed[16] .

The key point in the realization of fractance device is finding the rational approximation of the fractional order operator. There are many of the procedures exist for the calculation of rational approximations in both time and frequency domain. Oustaloup approximation, Carlson approximation, Mastuda Approximation, are some of the prominently used approximation techniques for the calculation of the rational approximation $[5,6,7,19,21,22]$. Even though there are several approximations possible, they are having their own advantages and disadvantages. In the Literature, in 2011 rational approximation using Continued Fraction Expansion method is proposed[21]. The rational approximation for $\alpha=1 / 2$, is presented in [21]. It is realized using operational amplifiers. But the realizations for $\alpha=1 / 3,1 / 4$ and other fractional orders are not yet realized. In this paper an attempt is made to realize fractional order operator or Fractance for $\alpha=-1 / 3,-1 / 4$ and its operation is verified in both time and frequency domains. A spice based software TINA is used for the simulation purpose.

The paper is organized as follows. In Section 2, the derivation of the rational approximation is presented. The realization using partial fraction expansions is presented in Section 3. Section 4 deals with the Active realization of the circuit using TINA-TI software. Finally conclusions are drawn in Section 5.

\section{RATIONAL APPROXIMATION}

In this section, a novel rational approximation proposed in [21] is studied for various values of fractional order $\alpha$. This proposed approximation is based on continued fraction expansion formula. It is given as[23,21], 


$$
=\frac{(1+x)^{\alpha}}{1-\frac{1}{1+\frac{1}{2} \frac{\alpha x}{1-\frac{1}{6} \frac{(\alpha+1) x}{1+\frac{1}{6} \frac{(\alpha-1) x}{1-\frac{1}{10} \frac{(\alpha+2) x}{1+\frac{1}{10} \frac{(\alpha-2) x}{1-\frac{1}{14} \frac{(\alpha-3) x}{1+\ldots \ldots \cdots \cdots}}}}}}}}
$$

This continued fraction expansion is convergence in the finite complex s-plane from $x=-\infty$ to $=-1$. For two number of terms of the expansion, first order rational order approximation is possible. It can also be observed that to have higher range of values of operation, higher order approximations are to be chosen. Substituting $x$ by $(s-1)$ and taking first ten terms of the series we obtain the truncated rational approximation expansion of $s^{\alpha}$ which is given as,

$S^{\propto}=\frac{P_{0} S^{5}+P_{1} S^{4}+P_{2} S^{3}+P_{3} S^{2}+P_{4} S+P_{5}}{Q_{0} S^{5}+Q_{1} S^{4}+Q_{2} S^{3}+Q_{3} S^{2}+Q_{4} S+Q_{5}}$

Where

$P_{0}=Q_{5}=-\propto^{5}-15 \propto^{4}-85 \propto^{3}-225 \propto^{2}-274 \propto-120$

$P_{1}=Q_{4}=5 \propto^{5}+45 \alpha^{4}+5 \propto^{3}-1005 \propto^{2}-3250 \propto-3000$

$P_{2}=Q_{3}=-10 \propto^{5}-30 \propto^{4}+410 \propto^{3}+1230 \propto^{2}-4000 \propto-12000$

$P_{3}=Q_{2}=10 \propto^{5}-30 \propto^{4}-410 \propto^{3}+1230 \propto^{2}+4000 \propto-12000$

$P_{4}=Q_{1}=-5 \propto^{5}+45 \propto^{4}-5 \propto^{3}-1005 \propto^{2}+3250 \propto-3000$

$P_{5}=Q_{0}=\alpha^{5}-15 \alpha^{4}+85 \alpha^{3}-225 \alpha^{2}+274 \propto-120$

It is also to be mentioned that the Eqn.(2) has been proved to be more efficient compared to Oustaloup approximation in [19] for a fractional order of $1 / 2$.

The values of the coefficients for various values of $\alpha$ is tabulated as in Table.1.The value of $\alpha$ is varied from 0.1 to 0.9 in steps of 0.1 .

Table.1. $5^{\text {th }}$ order Rational Approximation coefficients insteps of $\alpha$ as 0.1

\begin{tabular}{|c|l|l|l|l|l|l|}
\hline$\alpha$ & $\mathrm{P}_{0}$ & $\mathrm{P}_{1}$ & $\mathrm{P}_{2}$ & $\mathrm{P}_{3}$ & $\mathrm{P}_{4}$ & $\mathrm{P}_{5}$ \\
\hline 0.1 & 149.7365 & $3.3350 \mathrm{e}+03$ & $1.2387 \mathrm{e}+04$ & $1.1588 \mathrm{e}+04$ & $2.6851 \mathrm{e}+03$ & 94.7665 \\
\hline 0.2 & 184.5043 & $3.6901 \mathrm{e}+03$ & $1.2748 \mathrm{e}+04$ & $1.1154 \mathrm{e}+04$ & $2.3902 \mathrm{e}+03$ & 73.5437 \\
\hline 0.3 & 224.8689 & $4.0649 \mathrm{e}+03$ & $1.3078 \mathrm{e}+04$ & $1.0701 \mathrm{e}+04$ & $2.1152 \mathrm{e}+03$ & 55.8741 \\
\hline 0.4 & 271.4342 & $4.4593 \mathrm{e}+03$ & $1.3378 \mathrm{e}+04$ & $1.0230 \mathrm{e}+04$ & $1.8600 \mathrm{e}+03$ & 41.3338 \\
\hline 0.5 & 324.8438 & $4.8727 \mathrm{e}+03$ & $1.3643 \mathrm{e}+04$ & $9.7453 \mathrm{e}+03$ & $1.6242 \mathrm{e}+03$ & 29.5313 \\
\hline 0.6 & 385.7818 & $5.3045 \mathrm{e}+03$ & $1.3873 \mathrm{e}+04$ & $9.2489 \mathrm{e}+03$ & $1.4074 \mathrm{e}+03$ & 20.1062 \\
\hline 0.7 & 454.9746 & $5.7541 \mathrm{e}+03$ & $1.4066 \mathrm{e}+04$ & $8.7435 \mathrm{e}+03$ & $1.2092 \mathrm{e}+03$ & 12.7284 \\
\hline 0.8 & 533.1917 & $6.2206 \mathrm{e}+03$ & $1.4218 \mathrm{e}+04$ & $8.2317 \mathrm{e}+03$ & $1.0290 \mathrm{e}+03$ & 7.0963 \\
\hline 0.9 & 621.2470 & $6.7029 \mathrm{e}+03$ & $1.4330 \mathrm{e}+04$ & $7.7164 \mathrm{e}+03$ & 866.1229 & 2.9360 \\
\hline
\end{tabular}

By selecting $\alpha$ as $-1 / 3 \&-1 / 4$ the rational approximations will be given as,

$s^{-1 / 3}=\frac{11 s^{5}+440 s^{4}+2288 s^{3}+2860 s^{2}+910 s+52}{52 s^{5}+910 s^{4}+2860 s^{3}+2288 s^{2}+440 s+11}$

$s^{-1 / 4}=\frac{209 s^{5}+7315 s^{4}+35530 s^{3}+41990 s^{2}+12597 s+663}{663 s^{5}+12597 s^{4}+41990 s^{3}+35530 s^{2}+7315 s+209}$
The magnitude and phase responses for $\alpha=-1 / 3 \&-1 / 4$ are shown in Figs.1,2 and 3 respectively. From the figures it can be observed that the Fractance device works well in low frequency regions.

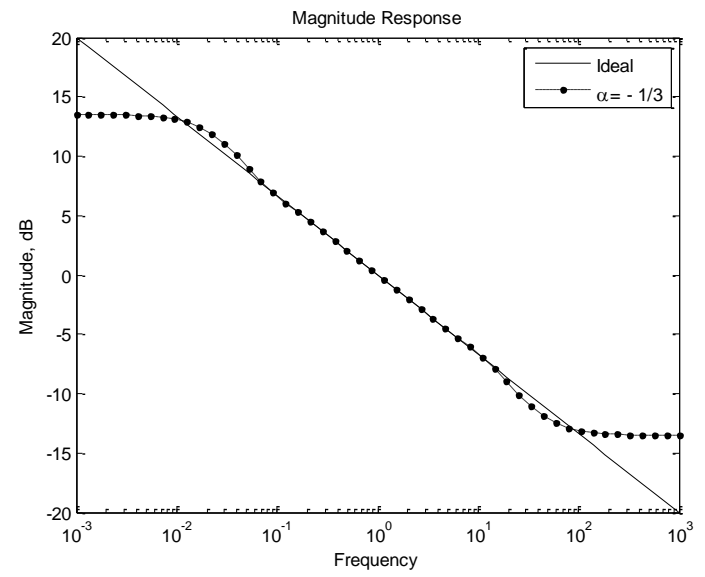

Fig.1.Magnitude response for $\alpha=-1 / 3$

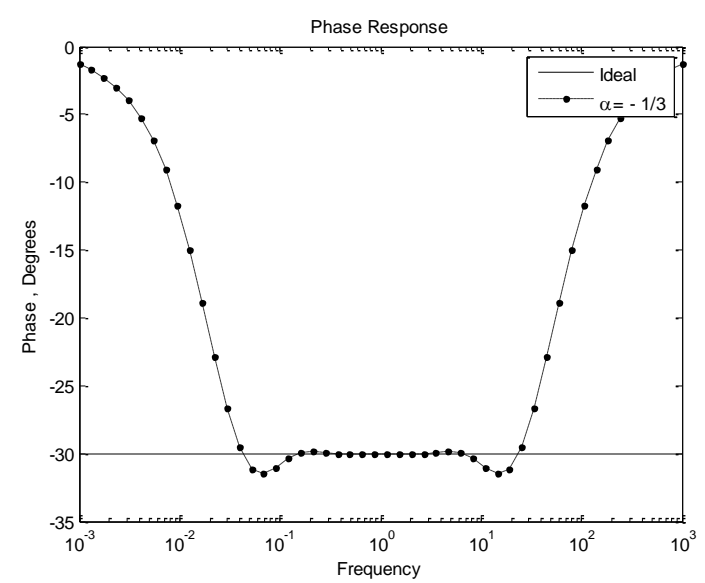

Fig.2.Phase response for $\alpha=-1 / 3$
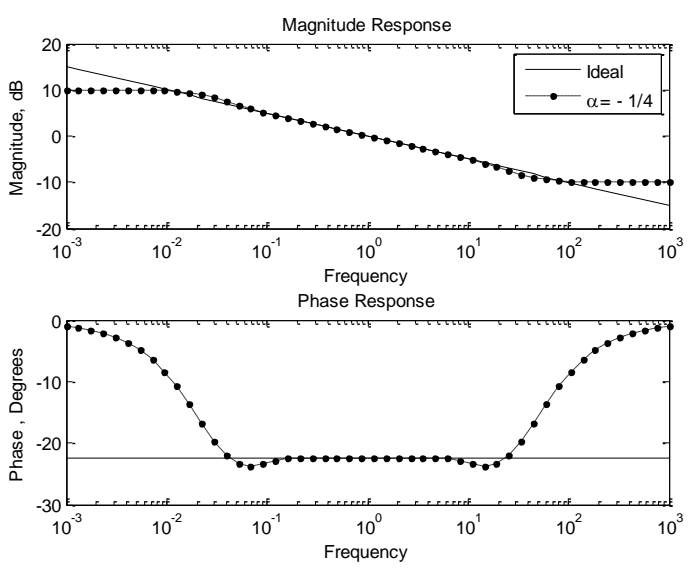

Fig.3.Magnitude and Phase responses for $\alpha=-1 / 4$

In this paper, the rational approximations obtained for $\alpha=-$ $1 / 3,-1 / 4$ has been chosen for realization of the Fractance device. 


\section{REALIZATION USING PARTIAL FRACTION EXPANSION}

The rational approximations obtained in the previous section need to be realized using the basic elements such as resistor and capacitors. In order to do this a MATLAB built in function residue () is used. As per the residue, the transfer function is expanded as,

$H(s)=R_{a}+\frac{1}{s C_{b}+R_{b}}+\frac{1}{s C_{c}+R_{c}}+---$

The values of $R_{a}, R_{b}, C_{b}$, ----- will be calculated by writing a MATLAB programme. For fifth order approximation the number of RC sections will be 5. The passive circuit realization for $5^{\text {th }}$ order transfer function is as shown in Fig.4.

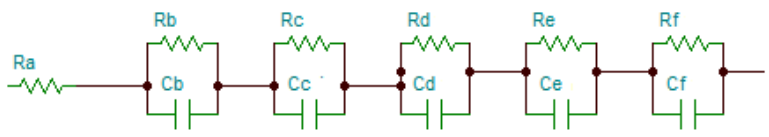

Fig.4.Passive realization of $5^{\text {th }}$ order approximation

The values of the resistances and capacitances for various values of $\alpha$ in steps of 0.1 are tabulated in Table.2.

Table.2.Elements values for various values of fractional order

\begin{tabular}{|c|c|c|c|c|c|c|c|c|c|c|c|}
\hline$\alpha$ & $\mathrm{R}_{\mathrm{a}}$ & $\mathrm{R}_{\mathrm{b}}$ & $C_{b}$ & $\mathrm{R}_{\mathrm{c}}$ & $\mathrm{C}_{\mathrm{c}}$ & $\mathrm{R}_{\mathrm{d}}$ & $\mathrm{C}_{\mathrm{d}}$ & $\mathrm{R}_{\mathrm{e}}$ & $\mathrm{C}_{\mathrm{e}}$ & $\mathrm{R}_{\mathrm{f}}$ & $\mathrm{C}_{\mathrm{f}}$ \\
\hline $\begin{array}{l}0 . \\
1\end{array}$ & $\begin{array}{l}0.63 \\
29\end{array}$ & $\begin{array}{l}0.18 \\
49\end{array}$ & $\begin{array}{l}0.30 \\
24\end{array}$ & $\begin{array}{l}0.11 \\
63\end{array}$ & $\begin{array}{l}2.75 \\
61\end{array}$ & $\begin{array}{l}0.11 \\
26\end{array}$ & $\begin{array}{l}9.39 \\
96\end{array}$ & $\begin{array}{l}0.15 \\
35\end{array}$ & $\begin{array}{l}23.2 \\
565\end{array}$ & $\begin{array}{l}0.379 \\
8\end{array}$ & $\begin{array}{l}61.4 \\
173\end{array}$ \\
\hline 0. & 0.39 & 0.25 & 0.24 & 0.19 & 1.73 & 0.21 & 5.13 & 0.34 & 11.1 & 1.094 & 24.7 \\
\hline 2 & 86 & 69 & 50 & 70 & 71 & 83 & 42 & 32 & 552 & 7 & 963 \\
\hline $\begin{array}{l}0 . \\
3\end{array}$ & $\begin{array}{l}0.24 \\
85\end{array}$ & $\begin{array}{l}0.26 \\
52\end{array}$ & $\begin{array}{l}0.26 \\
52\end{array}$ & $\begin{array}{l}0.24 \\
48\end{array}$ & $\begin{array}{l}1.49 \\
00\end{array}$ & $\begin{array}{l}0.31 \\
00\end{array}$ & $\begin{array}{l}3.82 \\
78\end{array}$ & $\begin{array}{l}0.56 \\
48\end{array}$ & $\begin{array}{l}7.28 \\
78\end{array}$ & 2.391 & $\begin{array}{l}13.4 \\
318\end{array}$ \\
\hline$\overline{0 .}$ & 0.15 & 0.23 & 0.32 & 0.26 & 1.47 & 0.38 & 3.30 & 0.80 & 5.49 & 4.722 & 8.22 \\
\hline 4 & 23 & 94 & 62 & 34 & 42 & 09 & 00 & 80 & 04 & 9 & 38 \\
\hline $\begin{array}{l}0 . \\
5\end{array}$ & $\begin{array}{l}0.09 \\
09\end{array}$ & $\begin{array}{l}0.19 \\
75\end{array}$ & $\begin{array}{l}0.43 \\
66\end{array}$ & $\begin{array}{l}0.25 \\
69\end{array}$ & $\begin{array}{l}1.60 \\
76\end{array}$ & $\begin{array}{l}0.42 \\
40\end{array}$ & $\begin{array}{l}3.14 \\
14\end{array}$ & $\begin{array}{l}1.05 \\
36\end{array}$ & $\begin{array}{l}4.55 \\
09\end{array}$ & 8.977 & $\begin{array}{l}5.38 \\
86\end{array}$ \\
\hline $\begin{array}{l}0 . \\
6\end{array}$ & 0.05 & $\begin{array}{l}0.15 \\
03\end{array}$ & $\begin{array}{l}0.63 \\
02\end{array}$ & $\begin{array}{l}0.22 \\
96\end{array}$ & $\begin{array}{l}1.91 \\
13\end{array}$ & $\begin{array}{l}0.43 \\
25\end{array}$ & $\begin{array}{l}3.26 \\
46\end{array}$ & $\begin{array}{l}1.26 \\
81\end{array}$ & $\begin{array}{l}4.09 \\
99\end{array}$ & $\begin{array}{l}17.05 \\
44\end{array}$ & $\begin{array}{l}3.68 \\
56\end{array}$ \\
\hline 0. & 0.02 & 0.10 & 0.99 & 0.18 & 2.50 & 0.40 & 3.74 & 1.39 & 4.05 & 33.63 & 2.59 \\
\hline 7 & 80 & 43 & 41 & 59 & 63 & 00 & 50 & 56 & 48 & 10 & 50 \\
\hline 0. & 0.01 & 0.06 & 1.79 & 0.13 & 3.79 & 0.32 & 4.96 & 1.34 & 4.60 & 73.26 & 1.86 \\
\hline 8 & 33 & 29 & 77 & 02 & 72 & 03 & 49 & 38 & 34 & 58 & 47 \\
\hline 0. & 0.00 & 0.02 & 4.40 & 0.06 & 7.84 & 0.18 & 8.97 & 0.96 & 7.06 & 210.3 & 1.35 \\
\hline 9 & 47 & 79 & 48 & 68 & 70 & 83 & 63 & 16 & 77 & 463 & 90 \\
\hline
\end{tabular}

The values of resistances and capacitances for $\alpha=-1 / 3,-1 / 4$ are tabulated in Table3.

Table.3.Element values for fractional orders -1/3, -1/4

\begin{tabular}{|l|l|l|}
\hline parameter & $\alpha=-1 / 3$ & $\alpha=-1 / 4$ \\
\hline $\mathrm{R}_{\mathrm{a}}$ & 0.2115 & 0.3152 \\
\hline $\mathrm{R}_{\mathrm{b}}$ & 0.2593 & 0.2668 \\
\hline $\mathrm{C}_{\mathrm{b}}$ & 0.2810 & 0.2496 \\
\hline $\mathrm{R}_{\mathrm{c}}$ & 0.2541 & 0.2248 \\
\hline $\mathrm{C}_{\mathrm{C}}$ & 1.4662 & 1.5719 \\
\hline
\end{tabular}

\begin{tabular}{|l|l|l|}
\hline $\mathrm{R}_{\mathrm{d}}$ & 0.3363 & 0.2663 \\
\hline $\mathrm{C}_{\mathrm{d}}$ & 3.5968 & 4.3300 \\
\hline $\mathrm{R}_{\mathrm{e}}$ & 0.6442 & 0.4505 \\
\hline $\mathrm{C}_{\mathrm{e}}$ & 6.5493 & 8.8094 \\
\hline $\mathrm{R}_{\mathrm{f}}$ & 3.0219 & 1.6486 \\
\hline $\mathrm{C}_{\mathrm{f}}$ & 11.2930 & 17.8691 \\
\hline
\end{tabular}

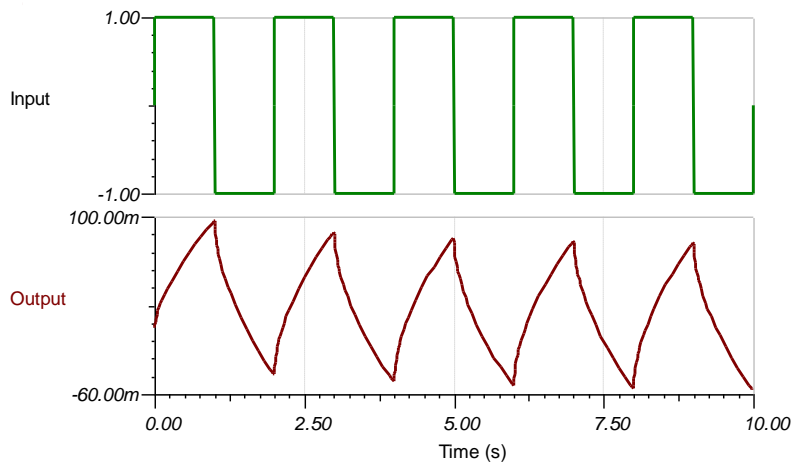

Fig.5.Input and output wave forms of Passive circuit at $\alpha=-1 / 3$ for a Square wave at $500 \mathrm{mHz}$

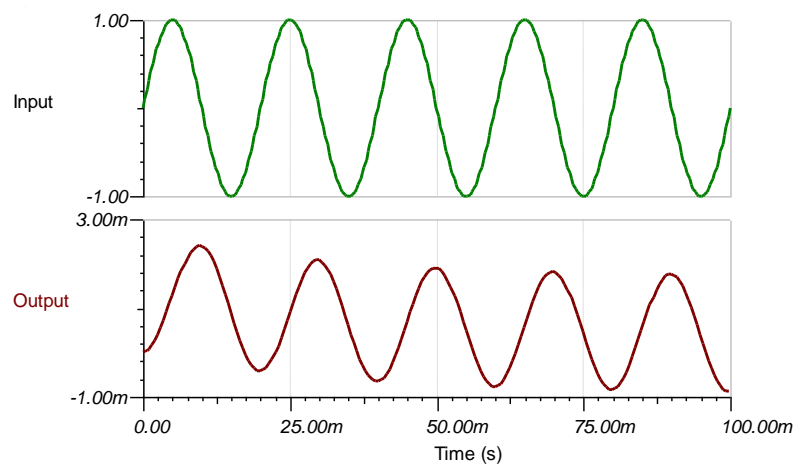

Fig.6.Input and output wave forms of Passive circuit at $\alpha=-1 / 3$ for a Sine wave at $50 \mathrm{~Hz}$.

\section{ACTIVE REALIZATION}

The circuit used for the active realization is as shown in Fig.7. Here $F$ stands for Fractance device and two operational amplifiers are used. First operational amplifier provides a phase shift which is nullified to zero when passed through an inverting amplifier connected to it. The value of $R_{\text {in }}$ is to be small and $\mathrm{R}$ is selected as $1 \mathrm{~K} \Omega$.

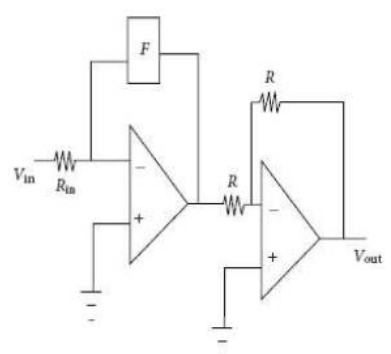

Fig.7.Active realization diagram 


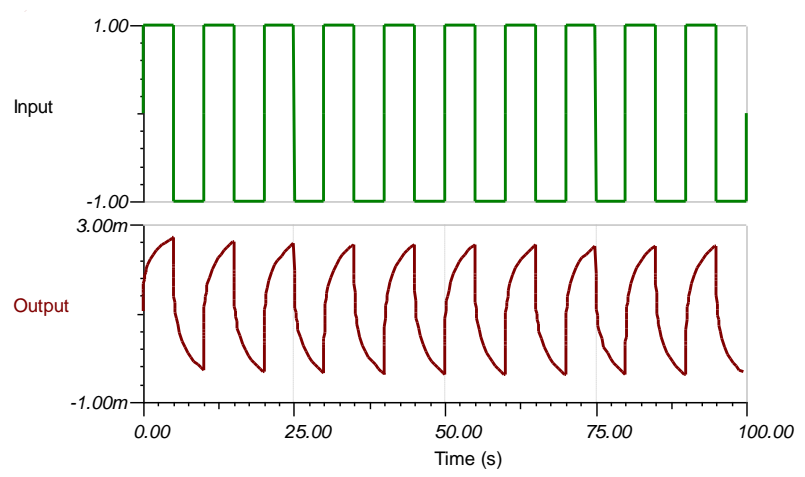

Fig.8.Input and output wave forms of Active circuit at $\alpha=$ $1 / 4$ for a Square wave at $100 \mathrm{mHz}$

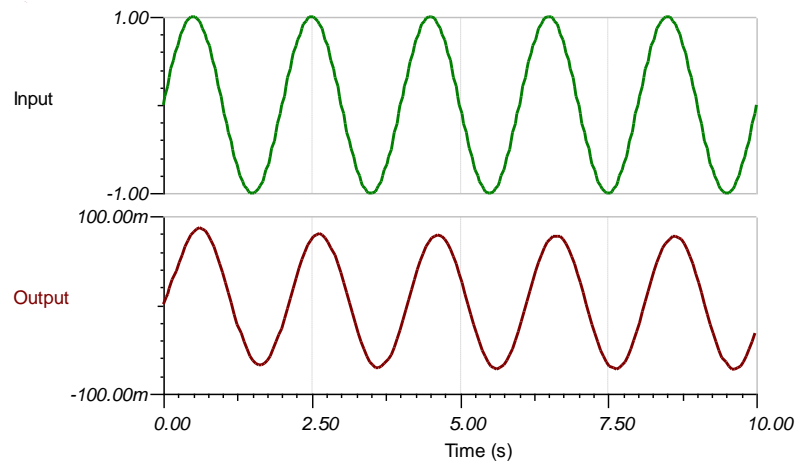

Fig.9.Input and output waveforms of the Active circuit $t$ $\alpha=-1 / 4$ for a Sine wave at $500 \mathrm{mHz}$

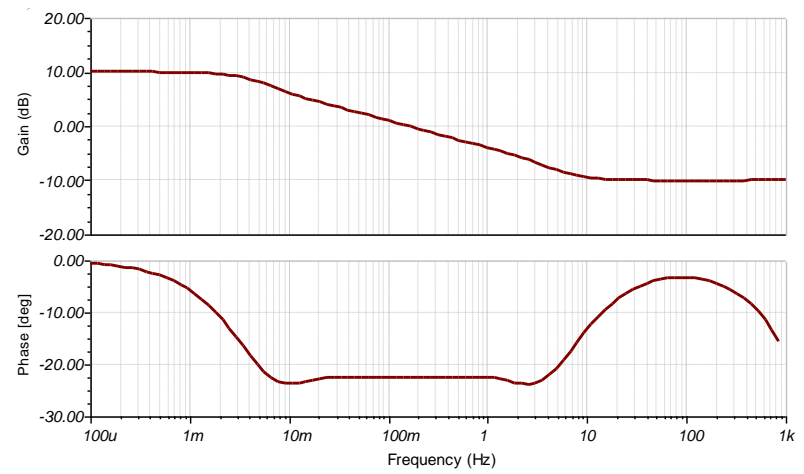

Fig.10.Bode curve of the circuit for $\alpha=-1 / 4$

\section{CONCLUSIONS}

Active and passive realization of the Fractance device for fifth order rational approximation at values of $\alpha=-1 / 3,-1 / 4$ is presented in this paper. Initially by making use of the continued fraction expansion formula the rational approximation for fifth order is calculated. Next, by making use of the MATLAB residue function, the passive circuit is realized. The realized passive circuit is converted into active one by making use of an operational amplifier.

Figs.1-3 present the magnitude, phase responses for the values of fractional order $-1 / 3,-1 / 4$. It can be observed that the Fractance device works good at low frequencies. The outputs of the passive realized circuits is shown in Figs.5 and 6. From the graphs it is evident that a square waveform is converted into a ramp signal, there is a phase shift for the sinusoidal input. Passive Circuit is converted into active one by making use of an operational amplifier. Figs.8,9 and 10 represents the output wave forms for different excitations and bode plot. Fig.10 is similar to the magnitude and phase response obtained theoretically in Fig.3.It can be observed that the experimental and theoretical results match each other.

\section{ACKNOWLEDGMENTS}

This work is carried out in support of the DST project SERB No. SB/FTP/ETA-048/2012 on dated 06-01-2017. Author thanks to the sponsoring agency for the support. Author also acknowledges the university authorities, Jawaharlal Nehru Technological University Kakinada, Kakinada, Andhra Pradesh, India for providing necessary facilities to carry out this work.

\section{REFERENCES}

[1] Oldham,K.B.,Spanier,J.1974 The Fractional Calculus, Academic Press, New York.

[2] I. Podlubny, 1999 Fractional Differential Equations, Academic Press, San Diego.

[3] L. Debnath, "Recent Applications of Fractional Calculus to Science and Engineering", IJMMS,2003,vol.54,pp.3413-3442.

[4] S. Manabe, "The non-integer integral and its application to control systems", JIEE, 1960, vol.80, pp.589-597.

[5] G.E.Carlson, C.A.halijak, "Approximation of a fractional capacitors $\left(1 / \mathrm{s}^{(1 / \mathrm{n})}\right.$ by a regular newton process", IEEE Transactions on Circuit theory,1964,pp.210-213.

[6] A.oustaloup, "Fractional order sinusoidal oscillators: optimization and their use in highly linear modulation"IEEE transactions on circuits andsystems, 1981,vol.CAS28, No.10.

[7] K.Matsuda, H.Fujii, "H1-optimized wave-absorbing control: analytical and experimental results", Journal of Guidance, Control, and Dynamics , 1993, pp.1146-1153.

[8] S.Westerlund, L. Ekstam, "Capacitor Theory ",IEEE Trans. on Dielectrics and Electrical Insulation, 1994, vol.1,no.5, pp. 826 - 839 .

[9] K.Sorimachi and M.Nakagawa, "Basic characteristics of a fractance device "- IEICE Transactions, 1998,vol.6.

[10] M. Sugi, Y. Hirano, Y. F. Miura , K. Saito,’Simulation of fractal immittance by analog circuits: An approach to the optimized circuits", IEICE Trans. Fundam. Electron.Commun. Comput. Sci. E82, 1999,pp.1627 1634.

[11] I. Petras, "The fractional-order controllers: methods for their synthesis and application"-,J. Electr. Eng., 1999, vol.50,pp.284 288.

[12] I.Podlubny, "Fractional-order systems and $\mathrm{PI}^{\lambda} \mathrm{D}^{\mu}$ controllers",IEEE transactions on Automatic control, 1999,Vol.44, pp.208 - 214.

[13] G. W. Bohannan,"Analog Realization of a Fractional Control Element Revisited", 27 October 2002, preprint (4 pages).

[14] W.Ahmad, El-Khaza, Fractional-order passive low-pass flters, Proceedings of the 2003 10th IEEE International 
Conference.

[15] A.Charef, "Analogue realisation of fractional order integartor, differentiator and fractional $\mathrm{PI}^{\lambda} \mathrm{D}^{\mu}$ controller" IEE proceedings of control theory Applications, 2006,Vol.153,No.6, pp.714-720.

[16] Pu, Yifei; Yuan, Xiao; Liao, Ke; Zhou, Jiliu; Zhang, Ni; $\mathrm{Pu}$, Xiaoxian; Zeng, Yi, A recursive two-circuits series analog fractance circuit for any order fractional calculus, Optical Information Processing. Edited by Sheng, Yunlong; Zhuang, Songlin; Zhang, Yimo. Proceedings of the SPIE, Volume 6027, 2006,pp. 509-519.

[17] Biswas. K, Sen., S, Dutta. P.K., "Realization of a Constant Phase Element and ItsPerformance Study in a Differentiator Circuit",IEEE Transactions on circuits and systems,2006,Volume 53, Issue 9, pp.802 - 806.

[18] B.T.Krishna,K.V.V.S.Reddy,S.Santha Kumari, "Time Domain Response Calculations of Fractance Device of order 1/2"-, Journal of Active and Passive Electronic
Devices, 2008, Volume 3, Issue3.

[19] B.T.Krishna,K.V.V.S.Reddy, "Active and Passive realization of fractance device of order 1/2"-, Journal of Active and Passive Electronic Components, 2008, Volume 2008,Article ID369421, 5 pages.

[20] B.T.Krishna,K.V.V.S.Reddy, "Analysis of Fractional order Low pass and High pass Filters", Journal of Electrical Engineering,Romania,2008,Vol. 8,Issue 1.

[21] B.T.Krishna, "Studies on Fractional order differentiators and integrators:a survey", signal processing,2011, vol.91, n0.3, pp.386-426.

[22] Ali Yüce , Nusret Tan, "Electronic realization technique for fractional order integrators", The journal of engineering,2020,vol.2020,no.5, pp.157-167.

[23] A.Khovanskii 1963 The Application of Continued Fractions and Their generalizations to Problems in Approximation Theory, by P.Noordhoff, Ltd. 